\title{
O transbordamento do PIB do Agronegócio do Brasil: uma análise da importância setorial via Matrizes de Insumo-Produto
}

\author{
The spillover of the Agribusiness GDP in Brazil: an analysis of the \\ sectoral importance via Input-Output Matrices \\ Antônio da Luz'1,2 (D), Adelar Fochezatto ${ }^{3}$ (D) \\ 1Programa de Pós-graduação em Economia do Desenvolvimento, Pontifícia Universidade Católica do Rio Grande do Sul (PUCRS), \\ Porto Alegre (RS), Brasil. E-mails: antonio@farsul.org.br; antonio@agromoney.net.br \\ ²Federação da Agricultura do Rio Grande do Sul (FARSUL), Porto Alegre (RS), Brasil. \\ 3Escola de Negócios, Programa de Pós-graduação em Economia do Desenvolvimento, Pontifícia Universidade Católica do Rio \\ Grande do Sul (PUCRS), Porto Alegre (RS), Brasil. E-mail: adelar@pucrs.br
}

\begin{abstract}
Como citar: Luz, A., \& Fochezatto, A. (2023). O transbordamento do PIB do Agronegócio do Brasil: uma análise da importância setorial via Matrizes de Insumo-Produto. Revista de Economia e Sociologia Rural, 61(1), e253226. https://doi.org/10.1590/1806-9479.2021.253226
\end{abstract}

Resumo: A importância do agronegócio na economia é um tema bastante estudado no contexto brasileiro. O objetivo deste estudo é contribuir com este tema fazendo uma mensuração simultânea do agronegócio nacional e de todas as Unidades da Federação nos anos de 2000 e 2010. Os resultados do estudo permitem verificar como o agronegócio agregado e seus componentes se distribuem no território nacional e ao longo do tempo. Para isso foram utilizadas informações compatibilizadas das matrizes de insumo-produto e de empregos da RAIS. Considerando apenas o ano de 2010, os resultados obtidos mostram que o agronegócio representa $21 \%$ do Valor Adicionado da economia brasileira, que São Paulo é a Unidade da Federação com maior participação no agronegócio nacional (26\%) e que Mato Grosso é a Unidade da Federação com maior participação do agronegócio na economia local (56\%).

Palavras-chave: agronegócio, matriz de insumo-produto, agropecuária, valor adicionado.

Abstract: The importance of agribusiness in the economy is a topic that has been widely studied in the Brazilian context. The aim of this study is to contribute to this theme by simultaneously measuring national agribusiness and all Federation Units in 2000 and 2010. The results of the study allow us to verify how aggregate agribusiness and its components are distributed in the national territory and to over time. For this, data from input-output matrices and RAIS were used. Considering only the year 2010, the results obtained show that agribusiness represents $21 \%$ of the Value Added of the Brazilian economy, that São Paulo is the Federation Unit with the largest participation in the national agribusiness (26\%) and that Mato Grosso is the Unit of Federation with the largest participation of agribusiness in the local economy (56\%).

Keywords: agribusiness, matrix input-output, agricultural, value added.

\section{Introdução}

A moderna agricultura originou o agronegócio e a sua constante modernização elevou o segmento ao status de importância econômica que atingiu 21,1\% do PIB brasileiro em 2018 (Confederação da Agricultura e Pecuária do Brasil, 2019). Em termos absolutos, o PIB do agronegócio do Brasil é maior que importantes economias mundiais, como, Israel, Irlanda, Hong Kong, Malásia, Dinamarca, Colômbia, Chile e outras (International Monetary Fund, 2019). Se o agronegócio brasileiro fosse um país, seria, em 2019, a 33ª economia do mundo, à frente de 165 economias. Na América Latina, o agronegócio brasileiro equivale, neste mesmo ano, a $86,57 \%$ do PIB da Argentina, segunda maior economia da região. Trata-se, portanto, de um 
segmento importante para a economia brasileira, justificando que mais estudos sejam feitos para melhor compreendê-lo.

O agronegócio é muito mais que agricultura e pecuária. Em linha com Davis \& Goldberg (1957), para estudá-lo é necessário considerar tudo o que é gerado em razão da agropecuária, como os segmentos de fertilizantes, químicos, fármacos, máquinas agrícolas, biotecnologia, energia elétrica, combustíveis etc. Também, é preciso considerar tudo o que é gerado a partir da produção agrícola ou pecuária, como as indústrias de alimentos, beneficiadores de grãos, frigoríficos, produtores de biocombustíveis, têxteis, dentre outras indústrias. Além disso, há que se considerar os segmentos do setor de serviços que transportam, armazenam, financiam, comercializam internamente e exportam a produção primária.

A literatura aplicada pertinente geralmente classifica essas atividades envolvidas no agronegócio em quatro grupos ou componentes: Núcleo do Agronegócio, contemplando as atividades agrícolas e pecuárias; Montante do Agronegócio, envolvendo os segmentos que fornecem insumos e capital para o Núcleo; Jusante do Agronegócio, abarcando os segmentos que recebem a produção do Núcleo como matéria-prima da sua própria produção; e Distribuição do Agronegócio, composta pelos segmentos do setor de serviços envolvidos.

O objetivo deste estudo é calcular o valor do agronegócio e de seus componentes simultaneamente para o Brasil e para as Unidades da Federação nos anos de 2000 e 2010. Este é o diferencial deste estudo, já que há, na literatura, diversas contribuições de cálculos estimativos do PIB do agronegócio do país ou de estados isoladamente. A regionalização do agronegócio e de seus componentes é feita utilizando os dados de emprego da Relação Anual de Informações Sociais - RAIS (Brasil, 2019) para os setores das matrizes de insumo-produto nas Unidades da Federação. A premissa básica para este rateio espacial do agronegócio e de seus componentes é a de que há uma relação constante entre capital e trabalho na função de produção do produto do agronegócio, independentemente da sua localização espacial. Para efetuar esta regionalização é necessária a compatibilização entre os setores da RAIS e das matrizes de insumo-produto do IBGE nos dois anos analisados.

Os resultados destes procedimentos possibilitam uma visão da distribuição espacial do agronegócio e de seus componentes. Observar a forma como o agronegócio brasileiro se espalha no território permite entender, dentro do Brasil, onde ele é mais forte e mais fraco, onde cresce mais ou menos e, sobretudo, onde ele está, onde se concentra e como se distribui. Essas informações podem ser de grande utilidade para compreender a agronegócio e para a formulação de políticas públicas.

Além desta introdução, este trabalho mais quatro seções. Na próxima seção é realizada uma revisão bibliográfica de estudos teóricos e empíricos. Na terceira seção são apresentados os procedimentos metodológicos e as bases de dados utilizadas no estudo. Na quarta seção é feita a análise dos resultados encontrados. Por fim, na última seção são apresentadas as principais conclusões do estudo.

\section{Revisão da literatura}

O conceito de agronegócio deve-se a Davis \& Goldberg (1957), compreendendo um conjunto de segmentos econômicos envolvidos nas cadeias de produção agropecuárias, desde os segmentos à montante até os à jusante. Malassis (1969) desenvolveu o conceito de cadeias agroindustriais. Esses conceitos têm em comum o fato de que a agricultura é analisada de forma integrada com outros setores a ela interligados dentro do sistema econômico. A ferramenta básica que fornece as informações de relações técnicas e de transações de compras e vendas entre setores na economia é a matriz de insumo-produto. 
No contexto da integração intersetorial, presente nos conceitos de agronegócio e de cadeias agroindustriais, uma referência importante é Guilhoto et al. (1994), que analisaram o papel dos índices de ligações interindustriais nas análises de insumo-produto, apresentando resultados para uma série de matrizes de insumo-produto para a economia brasileira (1959-1980). O objetivo principal do trabalho foi possibilitar uma visão mais ampla do papel das ligações interindustriais na economia em relação aos estudos anteriores sobre o tema, como Baer et al. (1987), Hewings et al. (1989) e Clements \& Rossi (1991, 1992).

Existem vários tipos de matrizes de insumo-produto, contemplando diferentes setores e regiões. Existem várias iniciativas destinadas a compilar matrizes de insumo-produto multirregionais (MRIO) em escala subnacional ou global. Este tipo de matriz contempla explicitamente as relações entre os setores e através das diferentes regiões. Por isso a sua construção demanda uma base de dados de comércio inter-regional de produtos entre setores produtivos e de bens finais. Lenzen et al. (2013) apresenta os resultados de um projeto de criação de uma MRIO com todos os países do mundo. A compatibilização de uma série de bases de dados gerou séries históricas matrizes compatíveis em nível global.

Na mesma linha, Dietzenbacher et al. (2013) descreve a construção de tabelas de insumoproduto mundiais. Tais tabelas fornecem os valores das transações entre 35 setores em 40 países mais um agregado para o 'Resto do Mundo'. Além das transações entre setores, estas tabelas apresentam os valores das vendas setoriais para diferentes componentes da demanda final. $\mathrm{O}$ artigo descreve os procedimentos metodológicos utilizados para harmonizar as informações das contas nacionais, tabelas de recursos e usos e estatísticas de comércio internacional para produzir séries temporais consistentes de tabelas de insumo-produto. Estas informações são muito usadas para estudos de cadeias globais de valor.

Em uma perspectiva multirregional internacional, Sesso Filho et al. (2022) estimaram o PIB do agronegócio para 63 países e o restante do mundo no período de 1995 a 2015. Os resultados mostraram que a participação do agronegócio no PIB mundial diminuiu de $18 \%$ para $15 \%$ no período. Considerando o ano de 2015, os maiores valores absolutos do PIB do agronegócio foram encontrados, pela ordem, na China, Estados Unidos, Índia, Japão e Brasil. No período analisado, o Brasil passou da oitava para a quinta posição no PIB do agronegócio. Os autores encontraram também que em países com maior IDH apresentaram maior participação da indústria e serviços na composição do PIB do agronegócio.

Especificamente para mensurar o PIB do agronegócio brasileiro, os trabalhos de Furtuoso (1998), Guilhoto et al. (2000), Nunes \& Contini (2001), Montoya \& Finamore (2001) e Porsse (2003) foram os pioneiros e trouxeram grande contribuição para a compreensão dos arranjos e conexões intersetoriais do setor. A partir destes, vários outros trabalhos foram feitos sobre a mensuração do agronegócio, com variações metodológicas e temáticas. Essa metodologia, com pequenos ajustes, passou a ser amplamente usada para produzir indicadores e inclusive para o acompanhamento conjuntural do setor (Gasques et al., 2004; Centro de Estudos Avançados em Economia Aplicada, 2017).

Uma das variantes é mensurar o agronegócio usando recortes alternativos das atividades agropecuárias. Neste sentido, utilizando a matriz de insumo-produto e do sistema de contas nacionais, Furtuoso \& Guilhoto (2003) apresentam nova metodologia para estimativa do PIB do agronegócio de uma economia nacional. Os autores estimam o PIB do agronegócio separados para dois grandes complexos, o dos produtos vegetais e o da pecuária. Cada um destes complexos foi dividido em quatro componentes: insumos para a agricultura; agricultura; indústria de base agrícola; e distribuição final. Os resultados indicaram uma participação de $27 \%$ do agronegócio no PIB do Brasil em 2000. O PIB do complexo dos Produtos Vegetais foi de $20 \%$ e o da Pecuária foi de $8 \%$, ambos em relação ao PIB do Brasil. 
Na linha de mensuração do agronegócio para recortes alternativos das atividades agropecuárias, Guilhoto et al. (2006), mensuraram o agronegócio da agricultura familiar no Brasil, para o período de 1995 a 2003. Seus resultados apontaram que cerca de um terço do agronegócio brasileiro advém da produção agropecuária realizada pelos agricultores familiares. Na época, os autores destacaram também que o desempenho da agropecuária familiar, e das atividades a ela articuladas, era superior ao do segmento patronal.

Em uma perspectiva multirregional subnacional, Peixoto et al. (2013) desenvolveram uma metodologia de análise do agronegócio em uma perspectiva inter-regional A mesma foi aplicada ao caso do Rio Grande do Sul-restante do Brasil, tendo por base uma Matriz de Insumo-Produto inter-regional de 2003. Os resultados indicaram que os segmentos do agronegócio respondem por $40 \%$ do valor adicionado do Rio Grande do Sul e por $23 \%$ no restante da economia brasileira. O estudo apontou também que $0,4 \%$ do valor adicionado do agronegócio do restante do Brasil advém das relações inter-regionais com o Rio Grande do Sul. Já as relações inter-regionais do restante do Brasil com o Rio Grande do Sul são responsáveis por $8 \%$ do valor adicionado do agronegócio gaúcho.

Para a mensuração do PIB do agronegócio para economias subnacionais isoladas, encontra-se vários trabalhos na literatura. Cruz et al (2009) analisaram as transformações do agronegócio de Minas Gerais, segundo as definições de agregado I (fornecedor de bens e insumos para a agropecuária), agregado II (agropecuária), agregado III (processamento e industrialização agrícolas) e agregado IV (distribuição agrícola). Para isso, os autores utilizaram a matriz de insumo-produto de Minas Gerais de 1999. Os resultados do estudo apontaram para uma participação do agronegócio de 30\% na economia local e participação de quase $10 \%$ no agronegócio nacional. Os autores concluem que a economia mineira possui características de economia alimentar industrializada, já que a participação da produção agropecuária ficou próxima de um terço do valor total do agronegócio. Em estudos similares, Araújo Neto \& Costa (2005) aplicam a metodologia para a economia de Pernambuco e concluem que o agronegócio representa $21 \%$ do PIB total do estado em 1999. Kureski et al (2020) avaliaram a participação do agronegócio na economia do Paraná no período de 2010 a 2015.

Uma aplicação alternativa é a de Montoya et al. (2016), que usaram o método de mensuração do agronegócio para analisar o seu consumo de energia e suas emissões de $\mathrm{CO}_{2}$. Para isso, construíram uma matriz energética com 56 setores consumidores, compatíveis com os 56 setores da matriz de insumo-produto do Brasil de 2009. Os resultados do estudo indicam que o agronegócio brasileiro responde por $21,3 \%$ do PIB, por 31,9\% dos empregos, por 34,7\% do consumo de energia e por $41 \%$ das emissões de $\mathrm{CO}_{2}$. Com isso, os autores concluem que a intensidade do consumo de energia e as emissões de $\mathrm{CO}_{2}$ no agronegócio são maiores que a média nacional. Entre os agregados do agronegócio, a agroindústria é a que proporcionalmente mais emite $\mathrm{CO}_{2}$, mas que, ao mesmo tempo, é o agregado que utiliza mais utiliza energia limpa e renovável.

A análise do mercado de trabalho no agronegócio é ainda escassa para o contexto brasileiro. O estudo de Castro et al. (2020) é um dos poucos trabalhos disponíveis na literatura. Os autores, além da mensuração da mão de obra existente no agronegócio brasileiro, analisaram a sua estrutura e as características dos trabalhadores envolvidos. Como principais resultados encontrados foram que em 2017 o agronegócio era responsável por 20\% do total de trabalhadores do País, que os empregos no setor eram predominantemente não qualificados, que havia uma alta participação de trabalhadores informais e que a remuneração média dos trabalhadores do setor era relativamente inferior à dos outros setores da economia. Verificaram também diferenças bastante significativas dessas variáveis entre os componentes do agronegócio. 


\section{Metodologia para a mensuração e regionalização do agronegócio}

Para o cálculo do PIB do agronegócio são considerados, de um lado, os segmentos industriais fornecedores de insumos, produtos e equipamentos, bem como, os serviços utilizados no processo de produção agropecuária, chamados aqui de agroserviços. Estes segmentos compõem a parte à Montante da agropecuária. Os segmentos que adquirem produtos da agropecuária, que são as agroindústrias, compõem a parte à Jusante da agropecuária. Os serviços envolvidos na distribuição dos produtos da agropecuária ou das agroindústrias compõem a parte da Distribuição. Além desses há a Agropecuária propriamente dita, considerada o Núcleo do agronegócio. A Figura 1 mostra a estrutura do agronegócio.

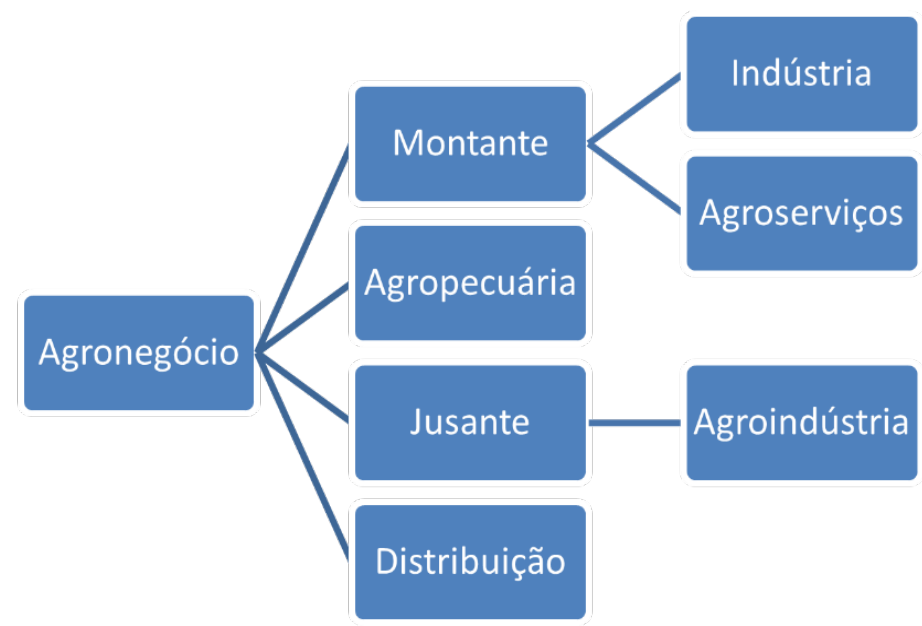

Figura 1 - Estrutura do agronegócio. Fonte: elaborado pelos autores.

A matriz de insumo-produto é a base de informação para a mensuração do PIB do agronegócio, pois ela quantifica as relações de compra e venda entre os setores da economia (Miller \& Blair, 2009). Dado que a matriz quantifica as relações intersetoriais, ela é usada também para mapear os setores que, por estarem fortemente interligados à agropecuária, fazem parte do agronegócio.

As principais referências para o cálculo no PIB do agronegócio são Furtuoso (1998), Guilhoto et al. (2000), Nunes \& Contini (2001) e Montoya \& Finamore (2001). Todas usam como base de dados a matriz de insumo-produto e convergem em relação a construção e cálculo do componente a montante do agronegócio. No entanto, no cálculo do segmento à jusante encontra-se diferenças entre esses estudos, sendo que o estudo de Montoya \& Finamore (2001) é mais abrangente em termos de setores usados no cálculo. Este estudo segue a classificação usada por estes autores.

Em relação ao componente à jusante da agropecuária, este estudo o divide em duas partes, atividades agroindústrias e atividades de distribuição. Esta divisão, no entanto, não altera o resultado final. Assim, além de separar segmentos distintos, a obtenção dessas duas partes permite uma análise mais rica da dinâmica espacial e temporal do agronegócio brasileiro. Assim, o PIB do agronegócio $\left(\mathrm{PIB}_{\mathrm{A}}\right)$ é obtido pela soma do valor adicionado do agronegócio a preços básicos $\left(V_{A}\right)$ e os impostos indiretos líquidos de subsídios $\left(T_{A}\right)$ :

$\mathrm{PIB}_{\mathrm{A}}=\mathrm{VA}_{\mathrm{A}}+\mathrm{T}_{\mathrm{A}}$ 
Neste estudo não são considerados os impostos. Portanto, a análise será feita em termos de valor adicionado do agronegócio brasileiro e sua distribuição regional. O VA $A_{A}$ é dado por:

$\mathrm{VA}_{\mathrm{A}}=\mathrm{VA}_{\mathrm{m}}+\mathrm{VA}_{\mathrm{n}}+\mathrm{VA}_{\mathrm{j}}+\mathrm{VA}_{\mathrm{d}}$

em que: $V A_{A}$ é o valor adicionado do Agronegócio; $V_{A}$ é valor adicionado do componente à montante da agropecuária; $V A_{n}$ é o valor adicionado da própria agropecuária (núcleo); $V A_{j}$ é o valor adicionado do componente à jusante da agropecuária; e $\mathrm{VA}_{d}$ é o valor adicionado pela distribuição final dos bens do agronegócio. Assim, diferentemente de alguns estudos sobre 0 tema, aqui o VA à jusante da agropecuária resulta do somatório do VA da agroindústria e do VA gerado no processo de distribuição. Cada um com uma metodologia de cálculo distinta.

Os segmentos que compõe o agronegócio à Montante são aqueles que fornecem integral ou parcialmente sua produção ao setor da agropecuária. A quantidade de segmentos pode variar conforme a matriz de insumo-produto utilizada para o cálculo, sendo que alguns dos segmentos podem não acrescentar valor algum ao agronegócio, uma vez que a produção do mesmo não seja utilizada como consumo intermediário na agropecuária. Nestes casos, ainda que o segmento conste na matriz, nenhum valor de seu VA é computado no agronegócio.

Dessa forma, o dispêndio da agropecuária em cada segmento é utilizado para determinar o quanto do VA do segmento fornecedor deve integrar o VA do componente à montante do agronegócio $\left(V A_{m}\right)$, uma vez que nem toda a produção do segmento será absorvida pela agropecuária como consumo intermediário. Assim, o VA $\mathrm{m}_{\mathrm{m}}$ calculado da seguinte forma:

$\mathrm{VA}_{\mathrm{m}}=\sum_{\mathrm{i}=1}^{\mathrm{n}}\left[\left(\frac{\mathrm{x}_{\mathrm{i} 1}}{\mathrm{X}_{\mathrm{i}}}\right) \mathrm{X}_{\mathrm{i}}-\left(\frac{\mathrm{x}_{\mathrm{i} 1}}{\mathrm{X}_{\mathrm{i}}}\right) \mathrm{C}_{\mathrm{i}}\right]$

em que: $V A_{m}$ é o valor adicionado do componente chamado de Montante do agronegócio; $x_{i 1}$ é a parcela do valor bruto da produção do segmento i absorvida como consumo intermediário na atividade 1 (agropecuária); $X_{i}$ é o valor bruto da produção do segmento i; $C_{i}$ é o consumo intermediário total do segmento i; e i = 1, 2, 3, ..., n são todos os setores da matriz de insumoproduto (65 setores).

A agropecuária é o centro do agronegócio. É a partir dela que se definem quais segmentos estão à montante e à jusante. Por essa razão, atribui-se a nomenclatura de Núcleo. Para computar

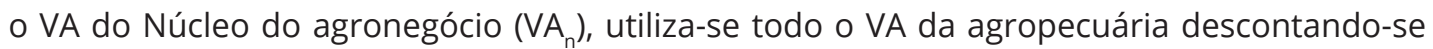
a parcela já computada como Montante, uma vez que a agropecuária utiliza produtos dela própria como consumo intermediário. Assim, o VA $A_{n}$ é calculado da seguinte forma:

$\mathrm{VA}_{\mathrm{n}}=\sum_{\mathrm{i}=1}^{\mathrm{n}} \mathrm{VA}_{\mathrm{i}}-\left\{\sum_{\mathrm{i}=1}^{\mathrm{n}}\left[\left(\frac{\mathrm{x}_{\mathrm{i} 1}}{\mathrm{X}_{\mathrm{i}}}\right) \mathrm{x}_{\mathrm{i}}-\left(\frac{\mathrm{x}_{\mathrm{i} 1}}{\mathrm{X}_{\mathrm{i}}}\right) \mathrm{C}_{\mathrm{i}}\right]\right\}$

em que: $V A_{n}$ é o valor adicionado do componente chamado de Núcleo do agronegócio; $x_{i 1}$ é a parcela do valor bruto da produção do segmento i absorvida como consumo intermediário na atividade 1 (agropecuária); $X_{i}$ é o valor bruto da produção do segmento i; $C_{i}$ é o consumo intermediário total do segmento i; e i = 1, 2, 3, ..., n são os setores da matriz de insumo-produto que compõem a agropecuária.

Neste estudo, o VA do componente à jusante da agropecuária é separado em duas partes. A primeira parte consiste no cômputo do VA compreendido pelo somatório dos segmentos conhecidos como agroindústrias, ou seja, indústrias que utilizam os produtos da agropecuária como insumo. A segunda parte compreende o VA dos serviços de distribuição dos produtos finais da agropecuária e das agroindústrias. Para calcular esta segunda parte utilizou-se o 
procedimento de Nunes \& Contini (2001) que computa para o agronegócio uma parcela do VA total dos serviços, a qual resulta da participação da demanda final de produtos agrícolas e agroindustriais no total da demanda final. Tem-se, portanto:

$\mathrm{VA}_{\mathrm{j}}=\sum_{\mathrm{i}=1}^{\mathrm{n}}\left[\mathrm{X}_{\mathrm{i}}-\mathrm{C}_{\mathrm{i}}\right]$

em que: $V A_{j}$ é o valor adicionado do componente chamado de Jusante do agronegócio; $X_{i}$ é o valor bruto da produção do segmento $i_{;} C_{i}$ é o consumo intermediário total do segmento $i_{\text {; }}$ e $i=1,2,3, \ldots, n$ são os setores que compõem a parte a jusante da agropecuária (agroindústrias).

$\mathrm{VA}_{\mathrm{d}}=\left(\frac{\mathrm{F}_{\mathrm{A}}}{\mathrm{F}}\right) \sum_{\mathrm{i}=1}^{\mathrm{n}}\left[\mathrm{X}_{\mathrm{i}}-\mathrm{C}_{\mathrm{i}}\right]$

onde: $\mathrm{VA}_{\mathrm{d}}$ é o valor adicionado do componente chamado de Distribuição final do agronegócio; $\mathrm{F}_{\mathrm{A}}$ é a soma do valor da demanda final de produtos agropecuários e das agroindústrias; $\mathrm{F}$ é o valor total da demanda final; $X_{i}$ é o valor bruto da produção do segmento $i_{;} C_{i}$ é o consumo intermediário total do segmento i; e i = 1, 2, 3, ..., n são os diferentes segmentos de serviços da economia, presentes na matriz de insumo-produto.

Os procedimentos descritos anteriormente permitem calcular o VA do agronegócio e de seus componentes, a partir das matrizes de insumo-produto brasileiras dos períodos analisados. Entretanto, isso não alcança o objetivo deste estudo, que é entender como esses indicadores se espalham no território brasileiro, ao nível das Unidades de Federação.

Para essas estimativas, parte-se da premissa básica de que há uma relação constante entre capital e trabalho na função de produção do produto do agronegócio, independentemente da localização. A partir dessa premissa, regionaliza-se os resultados dos cálculos utilizando os dados de emprego disponíveis na RAIS. Incialmente é feita a compatibilização dos setores das matrizes de insumo-produto com os setores da CNAE 2.0/Classe (ver Apêndice 1) e posteriormente, usando as proporções de empregos, é feito o rateio dos componentes do agronegócio para as Unidades da Federação.

Para o propósito de dimensionamento regional do agronegócio, a partir de matrizes de insumo-produto nacionais, há três bases de dados disponíveis que poderiam ser usadas, a saber: Pesquisa Nacional de Amostra de Domicílios (PNAD), Censo Demográfico (CD) e Relação Anual de Informações Sociais (RAIS). Dado que este estudo está restrito aos anos de 2000 e 2010, escolhidos em razão das divulgações de MIPs pelo IBGE no momento que o estudo foi realizado, não há PNADs disponíveis nestes anos, pois eles coincidem com anos censitários.

O Censo Demográfico potencialmente é a melhor base de dados para esta finalidade, pois não é amostra e nem tampouco subnotifica empregos por recepcionar também os informais. Entretanto, observando dados de ocupações, verifica-se variações percentuais alarmantes entre um Censo e outro e que não são acompanhadas por variações similares de área plantada ou produção nos mesmos períodos.

A RAIS é uma excelente base de dados de emprego. No entanto, a crítica mais frequente é a subnotificação de trabalhadores em razão da informalidade. Em que pese este ponto seja importante para estudos cujo foco é a compreensão das relações de trabalho em si, para este estudo essa crítica é uma questão menor, pois pressupõe-se que a informalidade é um problema nacional, já que as Leis, as tributações sobre o trabalho, fiscalizações e todos os demais incentivos à formalidade ou a informalidade são de âmbito nacional. Logo, é provável que a informalidade se distribua no Brasil de forma harmônica o suficiente para não alterar os resultados de alocação da MIP nas unidades subnacionais e os números de trabalhadores 
formais sejam suficientes para uma boa estimação. Diante dessas possibilidades, este estudo utiliza a base anual da RAIS como fonte principal de dados para a regionalização. No entanto, em razão da importância dos dados censitários, todos os cálculos utilizando a RAIS foram feitos também utilizando os Censos Demográficos de 2000 e 2010 do Instituto Brasileiro de Geografia e Estatística (2010)'1.

\section{Análise dos resultados}

Executando os procedimentos de cálculos descritos na metodologia, tem-se que, conforme apresentado na Tabela 1, o VA do agronegócio brasileiro atingiu 21\% do total em 2010, uma queda de dois pontos percentuais de participação em relação a 2000. É comum a percepção do crescimento das safras agrícolas, mas, o que cresce em função dela é mais relevante para este estudo. Nota-se, claramente, que a maior riqueza gerada pelo Agronegócio não está na Agropecuária, mas na Distribuição, eixo que representa quase 52\% do VA do agronegócio em 2010. De outro modo, pode-se dizer que a cada $R \$ 1,00$ gerado na Agropecuária, outros $R \$ 2,64$ são gerados distribuindo essa produção. Isso mostra a importância da industrialização antes da exportação.

Tabela 1 - Valor adicionado do agronegócio brasileiro, por segmento, comparado ao valor adicionado total.

\begin{tabular}{lcccc}
\multicolumn{1}{c}{ Resultados } & $\begin{array}{c}\text { Valor } \\
\text { (R\$ milhões) } \\
\mathbf{2 0 0 0}\end{array}$ & $\begin{array}{c}\text { Participação } \\
\mathbf{( \% )} \mathbf{2 0 0 0}\end{array}$ & $\begin{array}{c}\text { Valor } \\
\text { (R\$ milhões) } \\
\mathbf{2 0 1 0}\end{array}$ & $\begin{array}{c}\text { Participação } \\
\mathbf{( \% )} \mathbf{2 0 1 0}\end{array}$ \\
Montante & $13.416,46$ & 5,7 & $32.637,47$ & 4,7 \\
Agropecuária & $51.261,50$ & 22,0 & $137.684,25$ & 19,6 \\
Jusante & $65.200,05$ & 27,9 & $167.130,63$ & 23,8 \\
Distribuição & $103.591,71$ & 44,4 & $364.016,02$ & 51,9 \\
VA Agronegócio & $233.469,72$ & 100,0 & $701.468,38$ & 100,0 \\
VA Total & $1.021 .648,00$ & & $3.302 .840,00$ & \\
VA Agronegócio/VA Total & $23 \%$ & & $21 \%$ & \\
\hline
\end{tabular}

Fonte: Elaborado pelos autores.

A participação do agronegócio na economia nacional teve uma redução de dois pontos percentuais no período, passando de $23 \%$ para $21 \%$. Entre os componentes do agronegócio apenas a parte da Distribuição aumentou sua participação dentro do agronegócio, passando de $44 \%$ para $52 \%$. Isto de certa forma evidencia uma crescente complexidade do setor.

A Tabela 2 mostra a distribuição do VA do agronegócio nas Unidades da Federação. Observando os resultados do ano de 2010, em que pese as Unidades de Federação localizadas no CentroOeste sejam expoentes da produção de grãos, é em São Paulo (26,1\%), onde concentra-se a maior parte da riqueza gerada no agronegócio brasileiro, seguido por Minas Gerais (11,6\%), e pelos Estados do Sul, sendo Rio Grande do Sul (9,0\%), Paraná (8,3\%) e Santa Catarina $(5,8 \%)$. Pode-se dizer, portanto, que estes cinco estados concentram, somados, $60,7 \%$ do VA do agronegócio brasileiro.

1 Por falta de espaço, a regionalização do agronegócio e de seus componentes usando os dados dos Censos Demográficos não foi incluída neste trabalho. O leitor interessado pode solicitá-la diretamente aos autores. 
Tabela 2 - Valor adicionado do agronegócio, participação na economia da UF e participação no agronegócio nacional, 2000 e 2010.

\begin{tabular}{|c|c|c|c|c|c|c|c|}
\hline UF & $\begin{array}{c}\text { Valor } \\
\text { adicionado } \\
\text { do } \\
\text { agronegócio } \\
(2000)\end{array}$ & $\begin{array}{c}\text { Participação } \\
\text { na } \\
\text { economia } \\
\text { da UF (2000) }\end{array}$ & $\begin{array}{c}\text { Participação } \\
\text { no } \\
\text { agronegócio } \\
\text { nacional (A) } \\
(2000)\end{array}$ & $\begin{array}{c}\text { Valor } \\
\text { adicionado } \\
\text { do } \\
\text { agronegócio } \\
\text { (2010) }\end{array}$ & $\begin{array}{c}\text { Participação } \\
\text { na } \\
\text { economia } \\
\text { da UF (2010) }\end{array}$ & $\begin{array}{c}\text { Participação } \\
\text { no } \\
\text { agronegócio } \\
\text { nacional (B) } \\
(2010)\end{array}$ & A/B \\
\hline RO & $1.403,02$ & $33,3 \%$ & $0,60 \%$ & $5.633,04$ & $26,9 \%$ & $0,80 \%$ & 1,33 \\
\hline$A C$ & 303,81 & $18,0 \%$ & $0,13 \%$ & $1.394,86$ & $19,9 \%$ & $0,20 \%$ & 1,54 \\
\hline AM & 637,00 & $7,2 \%$ & $0,27 \%$ & $3.065,49$ & $7,6 \%$ & $0,44 \%$ & 1,63 \\
\hline $\mathrm{RR}$ & 90,32 & $13,2 \%$ & $0,04 \%$ & 567,30 & $11,8 \%$ & $0,08 \%$ & 2,00 \\
\hline PA & $4.251,78$ & $27,6 \%$ & $1,82 \%$ & $16.464,50$ & $23,9 \%$ & $2,35 \%$ & 1,29 \\
\hline AP & 219,38 & $10,2 \%$ & $0,09 \%$ & 531,89 & $8,2 \%$ & $0,08 \%$ & 0,89 \\
\hline TO & 712,50 & $21,9 \%$ & $0,31 \%$ & $4.300,30$ & $29,2 \%$ & $0,61 \%$ & 1,97 \\
\hline MA & $1.338,44$ & $14,1 \%$ & $0,57 \%$ & $6.141,74$ & $14,4 \%$ & $0,88 \%$ & 1,54 \\
\hline PI & 975,09 & $14,8 \%$ & $0,42 \%$ & $4.184,17$ & $17,0 \%$ & $0,60 \%$ & 1,43 \\
\hline CE & $5.788,09$ & $24,3 \%$ & $2,48 \%$ & $23.746,33$ & $28,5 \%$ & $3,39 \%$ & 1,37 \\
\hline $\mathrm{RN}$ & $2.739,10$ & $23,5 \%$ & $1,17 \%$ & $9.351,95$ & $21,4 \%$ & $1,33 \%$ & 1,14 \\
\hline PB & $2.686,98$ & $23,8 \%$ & $1,15 \%$ & $9.589,66$ & $25,3 \%$ & $1,37 \%$ & 1,19 \\
\hline PE & $8.787,74$ & $27,1 \%$ & $3,76 \%$ & $28.377,06$ & $27,0 \%$ & $4,05 \%$ & 1,08 \\
\hline$A L$ & $4.535,18$ & $49,3 \%$ & $1,94 \%$ & $10.805,50$ & $38,4 \%$ & $1,54 \%$ & 0,79 \\
\hline SE & $1.566,60$ & $20,1 \%$ & $0,67 \%$ & $5.948,54$ & $21,5 \%$ & $0,85 \%$ & 1,27 \\
\hline BA & $8.337,11$ & $18,1 \%$ & $3,57 \%$ & $34.425,20$ & $21,8 \%$ & $4,91 \%$ & 1,38 \\
\hline MG & $30.053,96$ & $27,6 \%$ & $12,87 \%$ & $81.047,75$ & $22,7 \%$ & $11,55 \%$ & 0,90 \\
\hline ES & $4.037,69$ & $21,0 \%$ & $1,73 \%$ & $12.350,59$ & $18,6 \%$ & $1,76 \%$ & 1,02 \\
\hline RJ & $11.896,11$ & $9,6 \%$ & $5,10 \%$ & $29.173,35$ & $8,2 \%$ & $4,16 \%$ & 0,82 \\
\hline SP & $61.666,49$ & $18,8 \%$ & $26,41 \%$ & $182.967,04$ & $18,3 \%$ & $26,08 \%$ & 0,99 \\
\hline PR & $19.596,03$ & $31,2 \%$ & $8,39 \%$ & $58.470,86$ & $28,1 \%$ & $8,34 \%$ & 0,99 \\
\hline SC & $14.555,17$ & $37,3 \%$ & $6,23 \%$ & $40.834,43$ & $29,9 \%$ & $5,82 \%$ & 0,93 \\
\hline RS & $22.125,78$ & $32,2 \%$ & $9,48 \%$ & $62.815,07$ & $30,8 \%$ & $8,95 \%$ & 0,94 \\
\hline MS & $6.002,80$ & $50,3 \%$ & $2,57 \%$ & $17.335,87$ & $45,3 \%$ & $2,47 \%$ & 0,96 \\
\hline MT & $5.921,60$ & $49,9 \%$ & $2,54 \%$ & $26.309,30$ & $56,2 \%$ & $3,75 \%$ & 1,48 \\
\hline GO & $8.630,53$ & $34,6 \%$ & $3,70 \%$ & $32.940,98$ & $35,6 \%$ & $4,70 \%$ & 1,27 \\
\hline DF & $1.319,74$ & $4,8 \%$ & $0,57 \%$ & $6.178,19$ & $7,4 \%$ & $0,88 \%$ & 1,54 \\
\hline Brasil & $233.469,72$ & $22,9 \%$ & $100,00 \%$ & $701.468,38$ & $21,2 \%$ & $100,00 \%$ & 1,00 \\
\hline
\end{tabular}

Fonte: elaboração dos autores. Nos Apêndice 2 e 3 estão as informações desagregadas para os quatro componentes do agronegócio, Montante, Agropecuária, Jusante e Distribuição.

Na Tabela 2 pode-se observar também a participação percentual do VA do agronegócio do estado no VA total deste estado, ou seja, a importância do agronegócio para aquela Unidade da Federação. Neste caso, o Centro-Oeste está na liderança. Observando os resultados do ano de 2010, em Mato Grosso, a participação do agronegócio chega a 56,2\% do VA total do estado, enquanto que em Mato Grosso do Sul o percentual é de 45,3\% e em Goiás é de 35,6\%. No Nordeste destaca-se Alagoas, onde o VA do agronegócio representa 38,4\% do VA do estado, demonstração da importância da produção sucroalcooleira. Para São Paulo, que produz a maior fatia do agronegócio brasileiro, o VA do agronegócio representa 18,3\% do seu VA total, neste mesmo ano, enquanto, no Sul a participação é, em média, 29,6\%. A Figura 2 proporciona uma visão espacial do VA do agronegócio nas Unidades da Federação e da sua participação nas respectivas economias.

Embora as Unidades de Federação do Norte não se destaquem pela concentração do Agronegócio Brasileiro e, tampouco, exibam um elevado percentual de participação do Agronegócio na sua economia, que, em média, foi de 18,2\%, em 2010, eles apresentaram 
maior aumento de participação no agronegócio nacional entre 2000 e 2010 (última coluna da Tabela 2). Entre todas as Unidades da Federação, Roraima e Tocantins foram as que mais aumentaram a participação no intervalo pesquisado. Mato Grosso também se destacou, pois, entre as Unidades de Federação com o Agronegócio mais desenvolvido, foi a que mais aumentou a participação no agronegócio nacional.

a) Valor Adicionado do agronegócio ( $\mathrm{R} \$$ milhões)

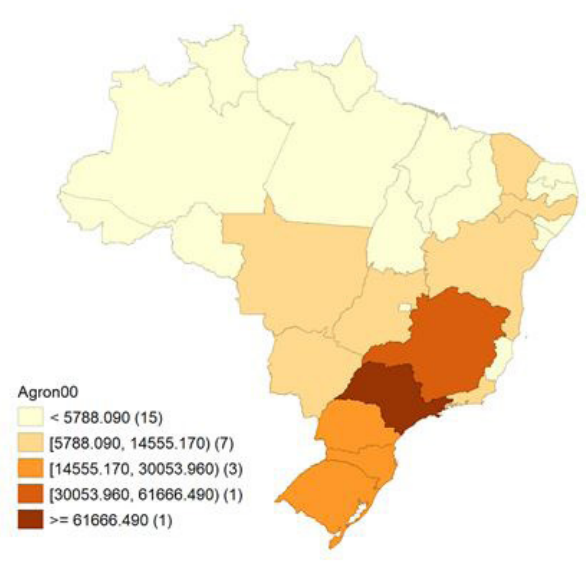

(2000)

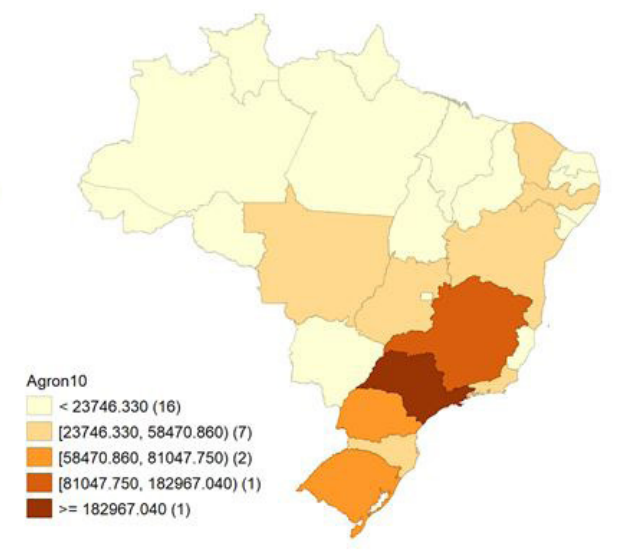

(2010)

b) Participação no valor adicionado total da UF (\%)



(2000)

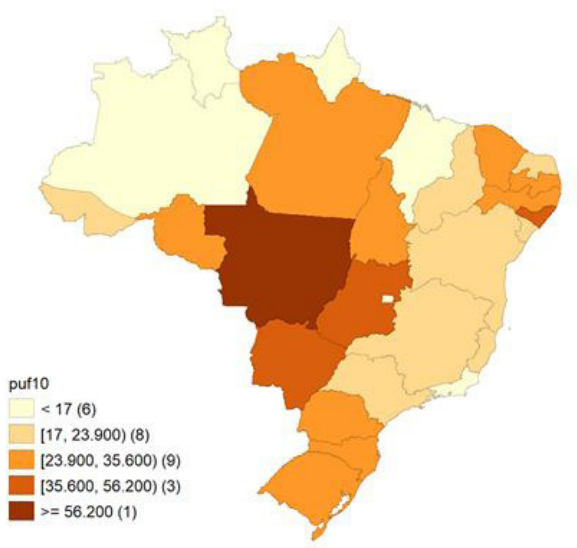

(2010)

Figura 2 - Distribuição do Valor Adicionado do Agronegócio Brasileiro nas Unidades da Federação, valor e participação na economia, 2000 e 2010. Fonte: elaborado pelos autores. Obs: cinco grupos de Unidades da Federação, definidos por quebras naturais.

Observando os dois mapas inferiores da Figura 2, é possível perceber um leve clareamento das cores dos mapas, indicando menor participação do agronegócio nas economias estaduais. Efetivamente houve no período uma pequena queda, como pode ser visto na última linha da Tabela 1. Isso, no entanto, não necessariamente está associado a um encolhimento do valor do agronegócio, mas o reflexo de um maior crescimento relativo dos demais setores da economia. Esse é um resultado comum no processo de desenvolvimento, já que os produtos alimentares possuem baixa elasticidade-renda da demanda. 


\section{Montante}

Os segmentos à Montante exercem um papel determinante para o desempenho da agropecuária. Além das indústrias e serviços fornecerem as tecnologias que garantem as altas e crescentes produtividades da produção, seus produtos costumam conter alto VA, gerando renda e riquezas através da sua própria produção. Como pode ser visto na Figura 3, essas empresas concentram-se no Sudeste e no Sul, com destaque para o estado de São Paulo, que concentra 33,1\% do VA da Montante do Brasil (ver Apêndices 2 e 3). Esse dado é compreensível, em razão da localização das matrizes de boa parte dessas empresas, sobretudo, químicas e farmacêuticas, além do Porto de Santos. Entre São Paulo, Minas Gerais (11,9\%), Paraná (7,5\%), Rio de Janeiro (7,2\%) e Rio Grande do Sul (6,6\%), tem-se 66,3\% do VA a Montante do Brasil. Ou seja, para ter um elevado VA do agronegócio, em termos absolutos, não basta o estado ter uma larga agropecuária, é, também, importante estar bem equipado com empresas fornecedoras de insumos e demais tecnologias. Um estado que expande a sua produção agropecuária sem expandir sua cadeia de fornecimento, importará estes insumos de outras Unidades da Federação, gerando renda do agronegócio, através da Montante, em outros estados.

Dessa forma, pode-se afirmar que a geração do VA do agronegócio não ocorre apenas no local em que se dá a produção agropecuária. Uma fazenda, localizada em Mato Grosso, que consome um agroquímico fabricado no Rio de Janeiro, industrializa sua produção em São Paulo e a distribui pelo Rio Grande do Sul, está gerando renda do agronegócio em todos os estados mencionados, através do Núcleo, da Montante, da Jusante e da Distribuição. Por outro lado, essas poderão ser oportunidades para o aparecimento de empresas dos demais segmentos do agronegócio mais próximos à produção agropecuária.

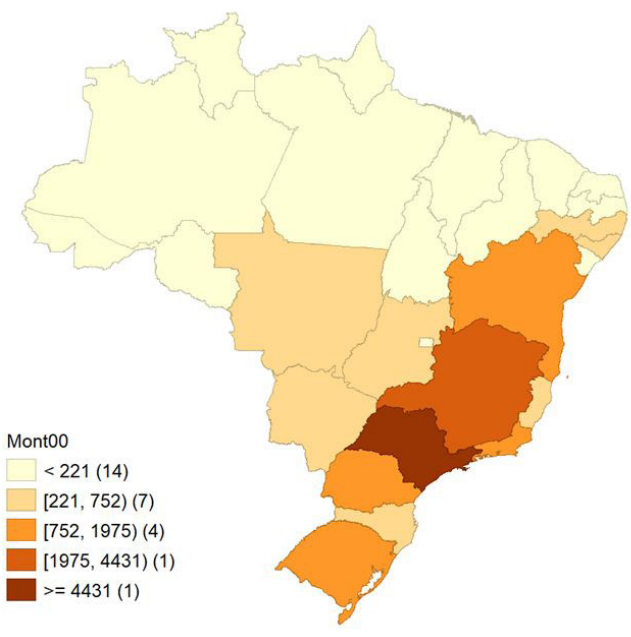

(2000)

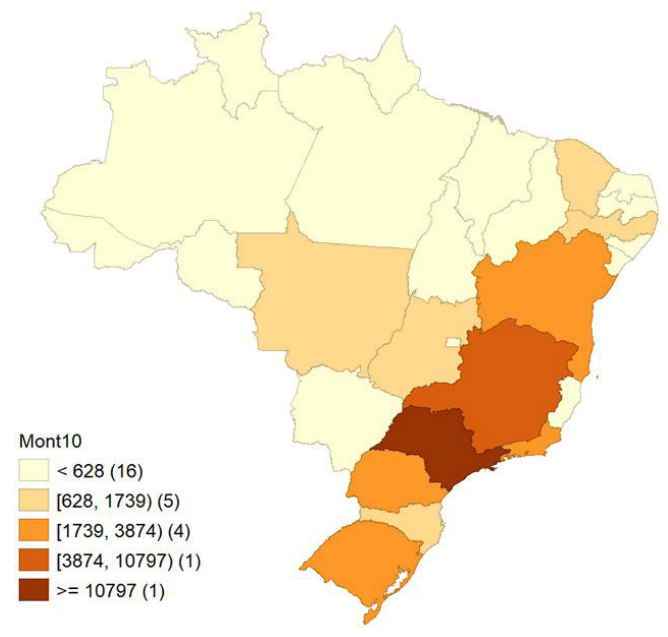

(2010)

Figura 3 - Distribuição do Valor Adicionado do Segmento à Montante do Agronegócio Brasileiro nas Unidades da Federação (Em R\$ milhões). Fonte: Elaborado pelos autores. Obs: cinco grupos de Unidades da Federação, definidos por quebras naturais.

Entre 2000 e 2010, não se notam mudanças substanciais, além da perda de participação do Mato Grosso do Sul e de Alagoas, e do ganho de importância do Ceará. Nota-se, também, a redução da importância do Espírito Santo, que, também, tem um importante porto, o que pode ser explicado pelo fim da "Guerra dos Portos". Estados com portos marítimos podem ter 
diferencial competitivo importante, uma vez que muitas das matérias-primas para a produção dos produtos da Montante são importadas.

\section{Agropecuária (Núcleo)}

O Núcleo retrata a agropecuária, a produção rural. O termo Núcleo não foi escolhido ao acaso, mas, para reafirmar a posição central em que este segmento se localiza na cadeia produtiva. É, inclusive, um equívoco comum pensar na agropecuária como setor primário, pelo menos a do Século XXI, que tem uma grande cadeia de fornecimento industrial e de serviços à Montante.

Há mudanças importantes na distribuição espacial do VA obtido no Núcleo entre 2000 e 2010. Percebe-se na Figura 4, por exemplo, a ascensão e a mudança de categoria dos estados do Mato Grosso, no Centro-Oeste; do Ceará, no Nordeste; e do Pará, no Norte. Nesse período, a produção agropecuária se desenvolveu e ganhou importância em todas as regiões. Esse movimento é positivo, pois é o fortalecimento e a expansão do Núcleo que garante o surgimento de empresas dos setores industriais e de serviços tanto à Jusante quanto à Montante da agropecuária, gerando VA para a economia, em diversos eixos dentro do agronegócio, não apenas dentro das fazendas.

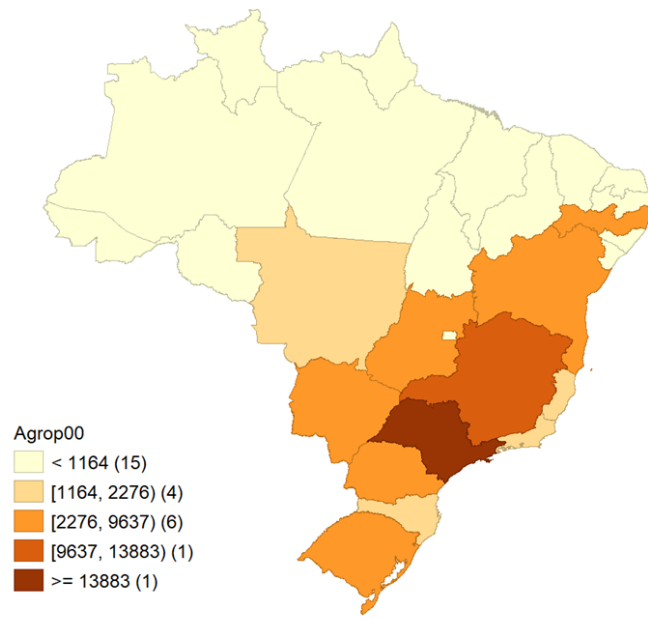

(2000)

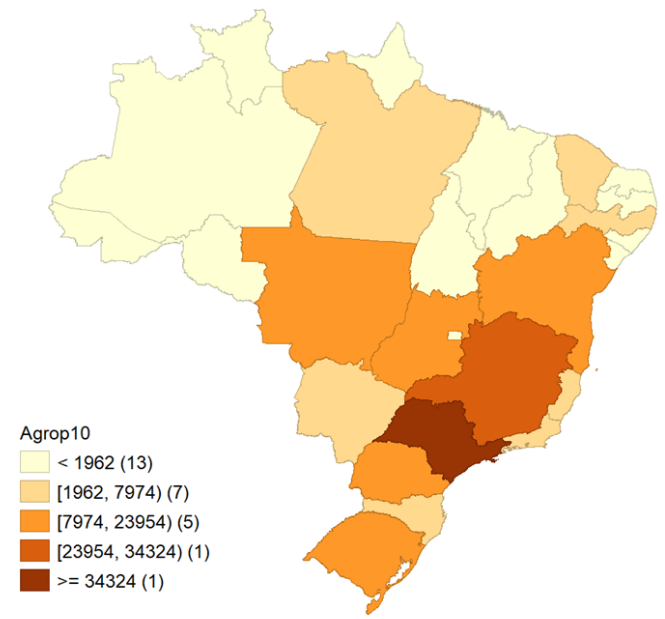

(2010)

Figura 4 - Distribuição do Valor Adicionado do Núcleo do Agronegócio Brasileiro nas Unidades da Federação (Em R\$ milhões). Fonte: elaborado pelos autores. Obs: cinco grupos de Unidades da Federação, definidos por quebras naturais.

O estado de São Paulo (24,9\%), embora não seja o maior produtor de grãos, concentra a maior fatia do VA do Núcleo do agronegócio brasileiro. Isso se deve principalmente à produção de cana-de-açúcar, laranja e pecuária de corte. Na sequência, aparece Minas Gerais (17,4\%), seguido do Paraná (7,2\%) e de Mato Grosso (6,5\%). Este último foi o estado que mais expandiu o Núcleo no período dentre os principais estados produtores agropecuários do Brasil.

\section{Jusante}

O segmento Jusante compreende as agroindústrias, indústrias de alimentos, cerealistas e demais empresas cuja matéria-prima seja a produção agropecuária. Embora, todas sejam 
indústrias, nem todas processam a produção. Pode-se dizer que para cada Real gerado em termos de VA no Núcleo, em 2010, outros $\mathrm{R} \$ 1,23$ foram gerados no VA do segmento à Jusante.

Em 2010, a Jusante concentrava-se em São Paulo (27\%), no Rio Grande do Sul (10\%), no Paraná (10\%), em Minas Gerais (10\%) e em Santa Catarina (9\%). No entanto, como mostra a Figura 5, no período analisado houve grande expansão deste componente em Goiás, Mato Grosso e Mato Grosso do Sul, no Centro-Oeste; Pará, no Norte; e Bahia, Alagoas, Paraíba e Rio Grande do Norte, no Nordeste. Os dados sugerem que o crescimento do Núcleo é precursor do crescimento do segmento à Jusante, ou seja, o desenvolvimento do Núcleo contribui para o aparecimento de empresas cuja proximidade da matéria-prima é fator fundamental para competitividade. É igualmente verdadeiro que a produção do Núcleo processada em outro estado gera VA do agronegócio em mais de um lugar.

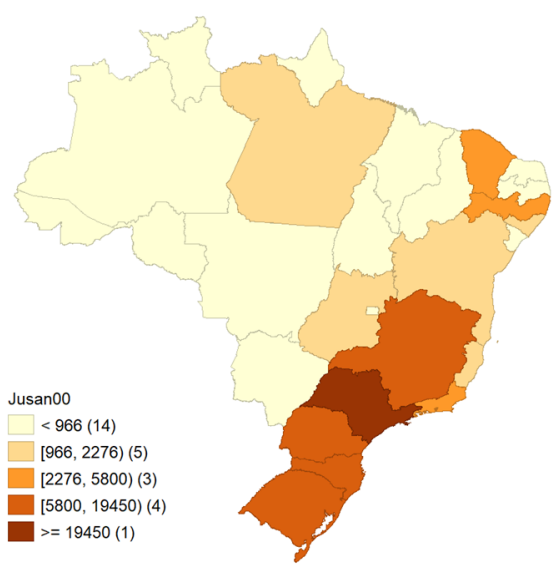

(2000)

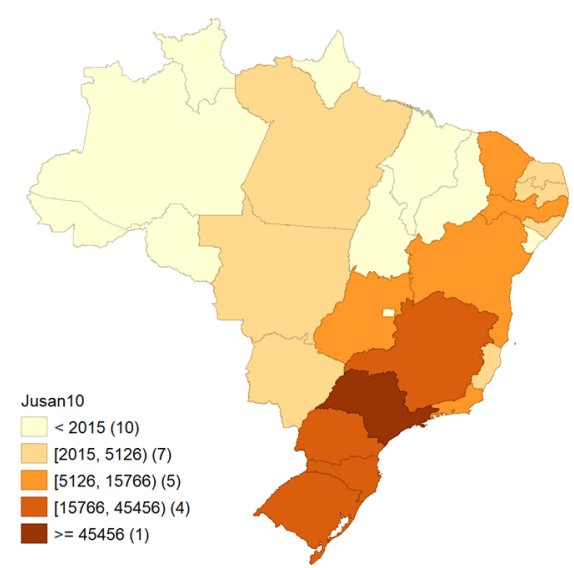

(2010)

Figura 5 - Distribuição do Valor Adicionado do Segmento Jusante do Agronegócio Brasileiro nas Unidades da Federação (Em R\$ milhões). Fonte: elaborado pelos autores. Obs: cinco grupos de Unidades da Federação, definidos por quebras naturais.

\section{Distribuição}

Apesar de sua importância na formação do agronegócio, o Núcleo não é o segmento que mais contribui para o VA do mesmo. A Distribuição, que contempla todos os processos que geram margem de comércio entre os segmentos do agronegócio, é o que mais gera VA. Para cada Real gerado no Núcleo, outros $R \$ 2,64$ são gerados pela Distribuição. No entanto, somente é possível existir Distribuição se houver produção no Núcleo, ou seja, a geração de VA pela agropecuária vai muito além da sua produção nas fazendas.

Podemos ver na Figura 6 que em 2010 a Distribuição ainda estava concentrada em São Paulo (25\%), Minas Gerais (10\%) e Rio Grande do Sul (10\%). No entanto, como pode ser visto na figura, Mato Grosso, no Centro-Oeste; e Bahia, Pernambuco e Rio Grande do Norte, no Nordeste tiveram crescimento importante da Distribuição. Os dados sugerem que à medida que o Núcleo aumenta, novas empresas surgem na Distribuição, ou seja, quanto mais produção agropecuária, maior tende a ser o número de empresas de outros setores (relacionados ao agronegócio) que surgem na economia, gerando valor, emprego e impostos. 


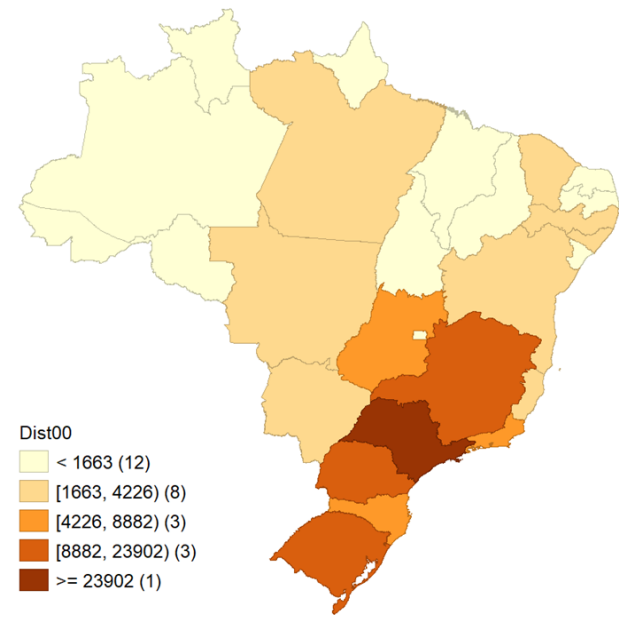

(2000)

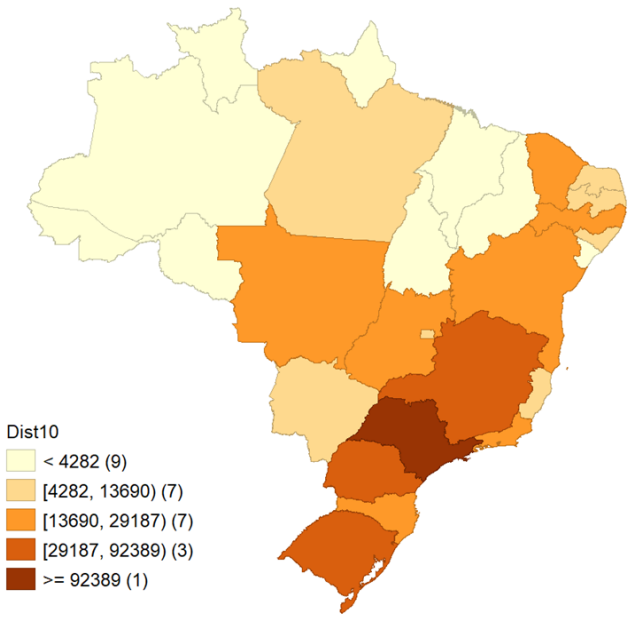

(2010)

Figura 6 - Distribuição do Valor Adicionado do Segmento Distribuição do Agronegócio Brasileiro nas Unidades da Federação (Em R\$ milhões). Fonte: elaborado pelos autores. Obs: cinco grupos de Unidades da Federação, definidos por quebras naturais.

A agropecuária é um importante setor da economia, tanto por sua capacidade de geração de renda quanto como fornecedora de alimentos. A sua produção é cada vez mais entrelaçada com as indústrias e os serviços. É o fornecimento de insumos, técnicas e altas tecnologias que garantem as notáveis e crescentes produtividades na agropecuária. Esse fornecimento, por sua vez, forma o segmento à Montante da agropecuária, gerando produção, renda e impostos nas indústrias e serviços. A agroindústria é quem recebe e processa a produção rural, gerando, também, riquezas no setor industrial. A Distribuição, que se baseia nas margens de comércio da demanda de cada segmento, gera, por sua vez, a maior parte da riqueza do agronegócio. Ou seja, a agropecuária é o Núcleo de um cinturão econômico relevante para a economia nacional e regional.

\section{Comentários finais}

O objetivo deste trabalho foi apurar o Valor Adicionado do agronegócio brasileiro nos anos de 2000 e 2010. Isso foi feito para o agronegócio como um todo e para os seus componentes Montante, Agropecuária, Jusante e Distribuição, usando metodologia já consagrada na literatura sobre o tema. A contribuição deste estudo foi o cálculo simultâneo do agronegócio e seus componentes para todas as Unidades da Federação.

Para o agronegócio brasileiro, os resultados encontrados foram uma participação de $23 \%$ do total da economia em 2000 e de $21 \%$ do total em 2010. Esses resultados não divergem dos valores encontrados por outros estudos similares. A pequena queda na participação verificada no período não surpreende. Se por um lado vemos um agronegócio cada vez mais moderno e interligado com outros setores da economia, por outro, percebe-se um crescimento relativamente maior de outros setores da economia, principalmente o setor de serviços.

Dentro do Valor Adicionado do agronegócio a maior parcela está na Distribuição, com mais de $50 \%$ do total em 2010, acompanhando uma tendência de aumento da importância dos serviços na economia. No período analisado, este foi o único componente que aumentou a sua 
participação dentro do agronegócio. O componente com menor participação é o Montante, com menos de 5\% em 2010.

A distribuição do Valor Adicionado do agronegócio brasileiro aponta para São Paulo como sendo a Unidade da Federação com a maior parcela, que foi de $26 \%$ em 2010 . No outro extremo estão Roraima e Amapá, ambos com menos de 1\% neste mesmo ano. Em geral, os estados menos significativos do agronegócio nacional foram os que mais aumentaram a sua participação nos dois anos analisados, destacando-se Roraima e Tocantins. São Paulo também é lugar que abriga a maior parcela do Valor Adicionado dos componentes do agronegócio, a saber: Montante (33\%), Agropecuária (25\%), Jusante (27\%) e Distribuição (25\%).

A participação do agronegócio nas economias estaduais é bastante heterogênea, variando de $7 \%$ no Distrito Federal a 56\% no Mato Grosso. No estado de São Paulo o agronegócio representa apenas $18 \%$ da economia. Este que, como foi visto anteriormente, é o estado responsável por boa parte do agronegócio nacional. Novamente fica evidente o fato de que à medida que a economia se desenvolve, o agronegócio cresce, mas proporcionalmente menos do que outros setores.

Em uma visão mais geral, pode-se concluir que: a distribuição do valor adicionado do agronegócio nacional é relativamente concentrada nas regiões Sudeste e Sul do Brasil, particularmente em São Paulo; a importância do agronegócio nas economias locais é relativamente mais acentuada na Região Centro-Oeste, especialmente em Mato Grosso; e os maiores ganhos de participação no agronegócio nacional nos dois anos analisados ocorreram em estados menos representativos deste setor, localizados nas Regiões Norte e Nordeste.

Por fim, cabe apontar as limitações dos procedimentos metodológicos adotados na regionalização do VAB do agronegócio. A primeira limitação é que foram utilizados apenas os vínculos da RAIS na regionalização. Isso pode gerar algumas distorções setoriais e regionais por conta das diferenças que podem existir em termos de produtividade e intensidade de uso dos fatores. Uma alternativa para trabalhos futuros poderia ser o uso de forma combinada dados de vínculos e de remunerações. Outra limitação do trabalho é o uso direto das matrizes de insumoproduto nacionais no processo de regionalização. Um procedimento alternativo poderia ser a compatibilização destas matrizes com as contas regionais por estado em cada ano analisado. Isto poderia gerar resultados mais precisos sobre a importância regional do agronegócio.

\section{Referências bibliográficas}

Araújo Neto, D. L., \& Costa, E. de F. (2005). Dimensionamento do PIB do agronegócio em Pernambuco. Revista de Economia e Sociologia Rural, 43(4), 725-757.

Baer, W., Fonseca, M. A. R., \& Guilhoto, J. J. M. (1987). Structural changes in Brazil's industrial economy, 1960-80. World Development, 15(2), 275-286.

Brasil. Ministério da Economia. (2019). Relação Anual de Informações Sociais. Brasília: Ministério da Economia. Recuperado em 12 de junho de 2021, de http://www.rais.gov.br/sitio/index.jsf

Castro, N. R., Barros, G. S. A. D. C., Almeida, A. N., Gilio, L., \& Morais, A. C. D. P. (2020). The Brazilian agribusiness labor market: measurement, characterization, and analysis of income differentials. Revista de Economia e Sociologia Rural, 58(1)

Centro de Estudos Avançados em Economia Aplicada - CEPEA. (2017). Metodologia: PIB do agronegócio brasileiro: base e evolução. Piracicaba: CEPEA.

Clements, B. J., \& Rossi, J. W. (1991). Interindustry linkages and economic development: the case of Brazil reconsidered. The Developing Economies, 29(2), 166-187. 
Clements, B. J., \& Rossi, J. W. (1992). Ligações interindustriais e setores-chave na economia brasileira. Pesquisa e Planejamento Econômico, 22(1), 101-124.

Confederação da Agricultura e Pecuária do Brasil - CNA. (2019). Boletim do PIB do agronegócio 2018. Recuperado em 12 de junho de 2021, de https://www.cnabrasil.org.br/boletins/pibdo-agronegocio-termina-2018-estavel

Cruz, A. C., Teixeira, E. C., \& Gomes, M. F. M. (2009). O PIB do agronegócio no estado de Minas Gerais: uma análise insumo-produto. Revista de Economia e Sociologia Rural, 47(4), 805-830.

Davis, J. H., \& Goldberg, R. A. (1957). A concept of agribusiness. Cambridge: Harvard University.

Dietzenbacher, E., Los, B., Stehrer, R., Timmer, M., \& de Vries, G. (2013). The construction of world input-output tables in the WIOD project. Economic Systems Research, 25, 71-98.

Furtuoso, M. (1998). O produto interno bruto do complexo agroindustrial brasileiro (Tese de doutorado). Universidade de São Paulo, Piracicaba.

Furtuoso, M. C. O., \& Guilhoto, J. J. M. (2003). Estimativa e mensuração do produto interno bruto do agronegócio da economia brasileira, 1994 a 2000. Revista de Economia e Sociologia Rural, 41(4), 803-827.

Gasques, J.G., Rezende, G.C. de, Villa Verde, C.M., Salerno, M.S., Conceição, J.C.P.R. \& Carvalho, J. C. S. (2004). Desempenho e crescimento do agronegócio no Brasil(Texto para Discussão, No. 1009). Brasília: IPEA.

Guilhoto, J. J. M., Silveira, F. G., Ichihara, S. M., \& Azzoni, C. R. (2006). A importância do agronegócio familiar no Brasil. Revista de Economia e Sociologia Rural, 44(3), 355-382.

Guilhoto, J., Furtuoso, M., \& Barros, C. (2000). O agronegócio na economia brasileira: 1994 a 1999. Brasília: Confederação Nacional da Agricultura.

Guilhoto, J., Sonis, M., Hewings, G. J., \& Martins, E. B. (1994). Índices de ligações e setores chave na economia brasileira: 1959-1980. Pesquisa e Planejamento Economico, 24, 287-314.

Hewings, G. J. D., Fonseca, M. A. R., Guilhoto, J. J. M., \& Sonis, M. (1989). Key sectors and structural change in the Brazilian economy: a comparison of alternative approaches and their policy implications. Journal of Policy Modeling, 11(1), 67-90.

Instituto Brasileiro de Geografia e Estatística - IBGE. (2010). Censo demográfico. Rio de Janeiro. Recuperado em 12 de junho de 2021, de https://www.ibge.gov.br/estatisticas/sociais/ populacao/25089-censo-1991-6.html?=\&t=o-que-e

International Monetary Fund - IMF. (2019). IMF Data Maper. Recuperado em 12 de junho de 2021, de https://www.imf.org/external/datamapper/NGDP_RPCH@WEO/OEMDC/ADVEC/ WEOWORLD

Kureski, R., Moreira, V.R., \& Veiga, C.P. (2020). Agribusiness participation in the economic structure of a Brazilian region: analysis of GDP and indirect taxes. Revista de Economia e Sociologia Rural, 58(3), e207669.

Lenzen, M., Moran, D., Kanemoto, K., \& Geschke, A. (2013). Building Eora: a global multi-region input-output database at high country and sector resolution. Economic Systems Research, 25, 20-49.

Malassis, L. (1969). La structure et l'évolution du complexe agri-industriel d'aprés la comptabilité nationale française. Économies et Sociéteés, 3(9), 1667-1687.

Miller, R., \& Blair, P. (2009). Input-output analysis foundations and extensions (2nd ed.). Cambridge: Cambridge University Press. 
Montoya, M. A., Pasqual, C. A., Lopes, R. L., \& Guilhoto, J. J. M. (2016). Consumo de energia, emissões de $\mathrm{CO} 2$ e a geração de renda e emprego no agronegócio brasileiro: uma análise insumo-produto. Economia Aplicada, 20(4), 383-412.

Montoya, M., \& Finamore, E. (2001). Evolução do PIB do agronegócio brasileiro de 1959 a 1995: uma estimativa na ótica do valor adicionado. Teoria e Evidência Econômica, 9(16), 9-24.

Nunes, P., \& Contini, E. (2001). Complexo agroindustrial brasileiro: caracterização de dimensionamento. Associação Brasileira de Agrobusiness.

Peixoto, F. C., Fochezatto, A., \& Porsse, A. A. (2013). Metodologia de análise inter-regional do agronegócio: aplicação ao caso do Rio Grande do Sul-restante do Brasil. Ensaios FEE, 34(2), 585-618.

Porsse, A. A. (2003). Notas metodológicas sobre o dimensionamento do PIB do Agronegócio do Rio Grande do Sul. Documentos FEE, 55, 1-34.

Sesso Filho, U. A., Borges, L. T., Sesso, P. P., Brene, P. R. A., \& Esteves, E. G. Z. (2022). Mensuração do complexo agroindustrial no mundo: comparativo entre países. Revista de Economia e Sociologia Rural, 60(1), e235345. 


\section{Apêndice 1 - Compatibilização dos setores da matriz de insumo-produto com a RAIS}

\section{Setores da matriz de insumo-produto}

0191: Agricultura, inclusive o apoio à agricultura e a pós-colheita

0192: Pecuária, inclusive o apoio à pecuária

0280: Produção florestal; pesca e aquicultura 0580:Extração de carvão mineral e de minerais não-metálicos

0680: Extração de petróleo e gás, inclusive as atividades de apoio

0791: Extração de minério de ferro, inclusive beneficiamentos e a aglomeração 0792: Extração de minerais metálicos nãoferrosos, inclusive beneficiamentos 1091: Abate e produtos de carne, inclusive os produtos do laticínio e da pesca 1092: Fabricação e refino de açúcar 1093: Outros produtos alimentares

1100: Fabricação de bebidas 1200: Fabricação de produtos do fumo 1300: Fabricação de produtos têxteis

1400: Confecção de artefatos do vestuário e acessórios

1500: Fabricação de calçados e de artefatos de couro

1600: Fabricação de produtos da madeira 1700: Fabricação de celulose, papel e produtos de papel

1800: Impressão e reprodução de gravações

1991: Refino de petróleo e coquerias

1992: Fabricação de biocombustíveis

2091: Fabricação de químicos orgânicos e inorgânicos, resinas e elastômeros

2092: Fabricação de defensivos, desinfestantes, tintas e químicos diversos

2093: Fabricação de produtos de limpeza, cosméticos/perfumaria e higiene pessoal

2100: Fabricação de produtos farmoquímicos e farmacêuticos

2200: Fabricação de produtos de borracha e de material plástico

2300: Fabricação de produtos de minerais nãometálicos

2491: Produção de ferro-gusa/ferroligas,

siderurgia e tubos de aço sem costura

2492: Metalurgia de metais não-ferrosos e a fundição de metais

\section{Setores da RAIS \\ (Código da CNAE 2.0 - Classe)}

01113; 01121; 01130; 01148; 01156; 01164; 01199; 01211; 01229; 01318; 01326; 01334; 01342; 01351; 01393; 01415; 01423; $01610 ; 01636$ 01512; 01521; 01539; 01547; 01555; 01598; 01628; 01709

02101; 02209; 02306; 03116; 03124; 03213; 03221

05003; 08100; 08916; 08924; 08932; 08991

06000; 09106

07103

07219; 07227; 07235; 07243; 07251; 07294; 09904

10112; 10121; 10139; 10201; 10511; 10520; 10538

$10716 ; 10724$

10619; 10627; 10635; 10643; 10651; 10660; 10694; 10813; 10821; 10911; 10929; 10937; 10945; 10953; 10961; 10996; 10317; 10325; 10333; 10414; 10422; 10431

11119; 11127; 11135; 11216; 11224

$12107 ; 12204$

13111; 13120; 13138; 13146; 13219; 13227 ; 13235; 13308; 13405; 13511; 13529; 13537; $13545 ; 13596$

14118; 14126; 14134; 14142; 14215; 14223

15106; 15211; 15297; 15319; 15327; 15335; 15394; 15408

16102; 16218; 16226; 16234; 16293

17109; 17214; 17222; 17311; 17320; 17338; 17419; 17427; 17494

18113; 18121; 18130; 18211; 18229; 18300

$19101 ; 19217 ; 19225$

$19314 ; 19322$

20118; 20126; 20134; 20142; 20193; 20215; 20223; 20291; 20312; 20321; 20339; 20401

20517; 20525; 20711; 20720; 20738; 20916; 20924; 20932; 20941; 20991

20614; 20622; 20631

$21106 ; 21211 ; 21220 ; 21238$

22111; 22129; 22196; 22218; 22226; 22234; 22293

23117; 23125; 23192; 23206; 23303; 23419; 23427; 23494; 23915; 23923; 23991

24113; 24121; 24211; 24229; 24237; 24245;

$24318 ; 24393$

24415; 24423; 24431; 24491; 24512; 24521

Fonte: elaboração dos autores. 


\section{Apêndice 1 - Continuação...}

\section{Setores da matriz de insumo-produto}

2500: Fabricação de produtos de metal, exceto máquinas e equipamentos

2600: Fabricação de equipamentos de informática, produtos eletrônicos e ópticos 2700: Fabricação de máquinas e equipamentos elétricos

2800: Fabricação de máquinas e equipamentos mecânicos

2991: Fabricação de automóveis, caminhões e ônibus, exceto peças

2992: Fabricação de peças e acessórios para veículos automotores

3000: Fabricação de outros equipamentos de transporte, exceto veículos automotores

3180: Fabricação de móveis e de produtos de indústrias diversas

3300: Manutenção, reparação e instalação de máquinas e equipamentos

3500: Energia elétrica, gás natural e outras utilidades

3680: Água, esgoto e gestão de resíduos

4180: Construção

4580: Comércio por atacado e varejo

4900: Transporte terrestre

5000: Transporte aquaviário

5100: Transporte aéreo

5280: Armazenamento, atividades auxiliares dos transportes e correio

5500: Alojamento

Fonte: elaboração dos autores.
Setores da RAIS

(Código da CNAE 2.0 - Classe)

25110; 25128; 25136; 25217; 25225; 25314; 25322; 25390; 25411; 25420; 25438; 25501; 25918; 25926; 25934; 25993

26108; 26213; 26221; 26311; 26329; 26400; 26515; 26523; 26604; 26701; 26809

$27104 ; 27210 ; 27228 ; 27317 ; 27325 ; 27333$; $27406 ; 27511 ; 27597 ; 27902$

28119; 28127; 28135; 28143; 28151; 28216; 28224; 28232; 28241; 28259; 28291; 28313; 28321; 28330; 28402; 28518; 28526; 28534; 28542; 28615; 28623; 28631; 28640; 28658; 28666; 28691

29107; 29204

29301; 29417; 29425; 29433; 29441; 29450; 29492; 29506

30113; 30121; 30318; 30326; 30415; 30423; 30911; 30920; 30997

$31012 ; 31021 ; 31039 ; 31047 ; 32116$; 32124; 32205; 32302; 32400; 32507; 32914; 32922; 32990

33112; 33121; 33139; 33147; 33155; 33163; 33171; 33198; 33210; 33295; 95118; 95126; 95215; 95291

35115; 35123; 35131; 35140; 35204; 35301

36006; 37011; 37029; 38114; 38122; 38211; 38220; 38319; 38327; 38394; 39005

41204; 42111; 42120; 42138; 42219; 42227; 42235; 42910; 42928; 42995; 43118; 43126; 43134; 43193; 43215; 43223; 43291; 43304; 43916; 43991

45111; 45129; 45200; 45307; 45412; 45421; 45439; 46117; 46125; 46133; 46141; 46150; 46168; 46176; 46184; 46192; 46214; 46222; $46231 ; 46311 ; 46320 ; 46338 ; 46346 ; 46354$; 46362; 46371; 46397; 46419; 46427; 46435; 46443; 46451; 46460; 46478; 46494; 46516; 46524; 46613; 46621; 46630; 46648; 46656; 46699; 46711; 46729; 46737; 46745; 46796; 46818; 46826; 46834; 46842; 46851; 46869; 46877; 46893; 46915; 46923; 46931; 47113; 47121; 47130; 47211; 47229; 47237; 47245; 47296; 47318; 47326; 47415; 47423; 47431; 47440; 47512; 47521; 47539; 47547; 47555; 47563; 47571; 47598; 47610; 47628; 47636; 47717; 47725; 47733; 47741; 47814; 47822; 47831; 47849; 47857; 47890; 47903

49116; 49124; 49213; 49221; 49230; 49248; 49299; 49302; 49400; 49507

50114; 50122; 50211; 50220; 50301; 50912; 0998

51111; 51129; 51200; 51307

52117; 52125; 52214; 52222; 52231; 52290; $52311 ; 52320 ; 52397 ; 52401 ; 52508 ; 53105 ; 53202$ 55108; 55906 


\section{Apêndice 1 - Continuação...}

\section{Setores da matriz de insumo-produto}

5600: Alimentação

5800: Edição e edição integrada à impressão

5980: Atividades de televisão, rádio, cinema e gravação/edição de som e imagem

6100: Telecomunicações

6280: Desenvolvimento de sistemas e outros serviços de informação

6480: Intermediação financeira, seguros e previdência complementar

6800: Atividades imobiliárias

6980: Atividades jurídicas, contábeis, consultoria e sedes de empresas

7180: Serviços de arquitetura, engenharia, testes/ análises técnicas e $P$ \& D

7380: Outras atividades profissionais, científicas e técnicas

7700: Aluguéis não-imobiliários e gestão de ativos de propriedade intelectual

7880: Outras atividades administrativas e serviços complementares

8000: Atividades de vigilância, segurança e investigação

8400: Administração pública, defesa e seguridade social

8591: Educação pública

8592: Educação privada

8691: Saúde pública

8692: Saúde privada

9080: Atividades artísticas, criativas e de espetáculos

9480: Organizações associativas e outros serviços pessoais

9700: Serviços domésticos

Fonte: elaboração dos autores.
Setores da RAIS (Código da CNAE 2.0 - Classe)

$56112 ; 56121 ; 56201$

58115; 58123; 58131; 58191; 58212; 58221; 58239; 58298

59111; 59120; 59138; 59146; 59201; 60101; $60217 ; 60225$

$61108 ; 61205 ; 61302 ; 61418 ; 61426 ; 61434 ; 61906$ 62015; 62023; 62031; 62040; 62091; 63119; $63194 ; 63917 ; 63992$

64107; 64212; 64221; 64239; 64247; 64310; 64328; 64336; 64344; 64352; 64361; 64379; 64387; 64409; 64506; 64611; 64620; 64638; $64701 ; 64913 ; 64921 ; 64930 ; 64999 ; 65111$; $65120 ; 65201 ; 65308 ; 65413 ; 65421 ; 65502$; $66118 ; 66126 ; 66134 ; 66193 ; 66215 ; 66223$; $66291 ; 66304$

$41107 ; 68102 ; 68218 ; 68226$

69117; 69125; 69206; 70204; 70107

71111; 71120; 71197; 71201; 72100; 72207

73114; 73122; 73190; 73203; 74102; 74200; 74901

77110; 77195; 77217; 77225; 77233; 77292; 77314; 77322; 77331; 77390; 77403; 78108; $78205 ; 78302$

$81117 ; 81125 ; 81214 ; 81222 ; 81290 ; 81303 ;$ $82113 ; 82199 ; 82202 ; 82300 ; 82911 ; 82920$; $82997 ; 79112 ; 79121 ; 79902 ; 75001$

$80129 ; 80111 ; 80200 ; 80307$

$84116 ; 84124 ; 84132 ; 84213 ; 84221 ; 84230 ;$ $84248 ; 84256 ; 84302$

85112

$85121 ; 85139 ; 85201 ; 85317 ; 85325 ; 85333$; 85414; 85422; 85503; 85911; 85929; 85937; 85996 86101

$86216 ; 86224 ; 86305 ; 86402 ; 86500 ; 86607$; $86909 ; 87115 ; 87123 ; 87204 ; 87301 ; 88006$ 90019; 90027; 90035; 91015; 91023; 91031; 92003; 93115; 93123; 93131; 93191; 93212; 93298 94111; 94120; 94201; 94308; 94910; 94928; 94936; 94995 96017; 96025; 96033; 96092; 97005; 99008 


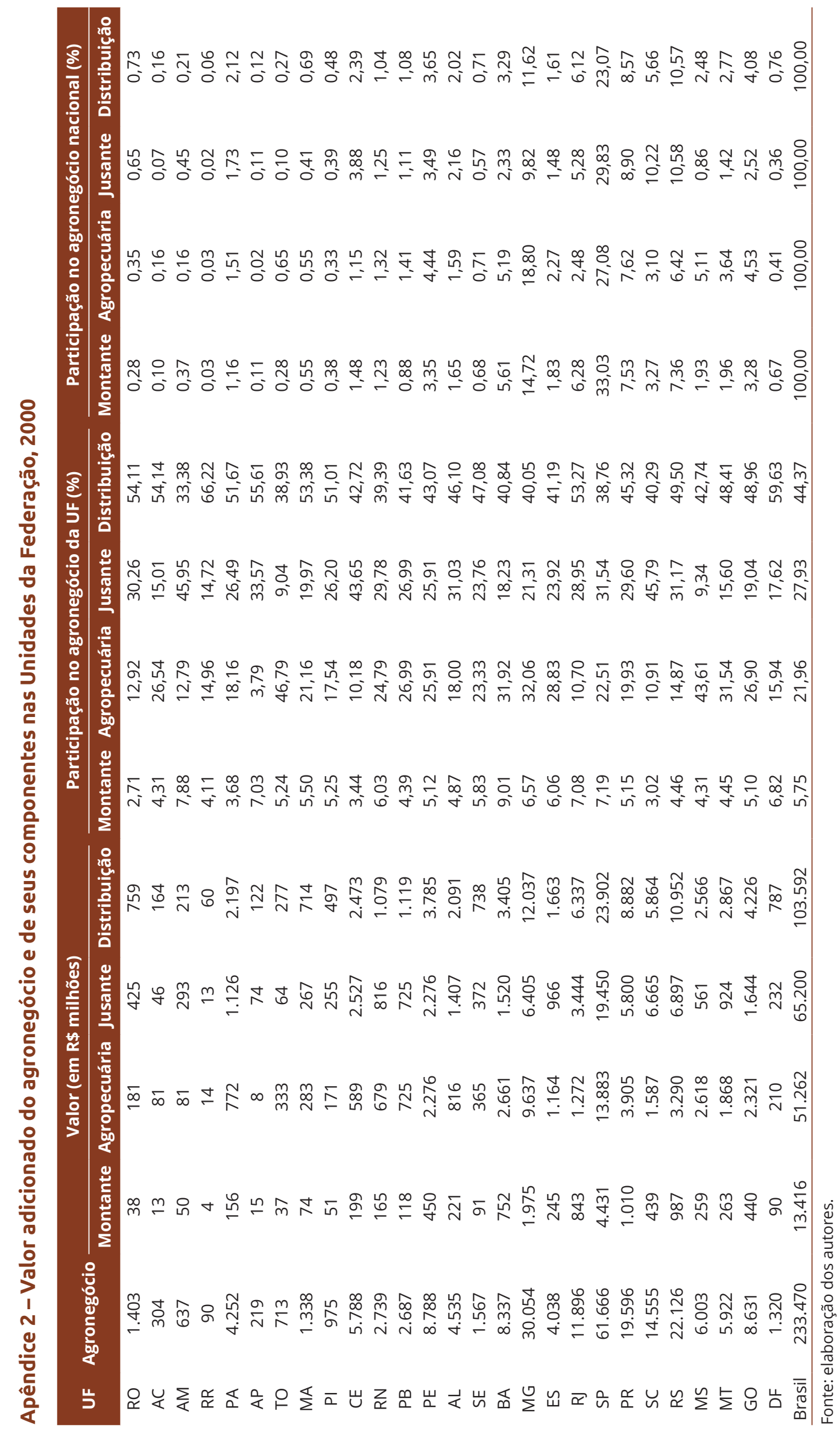






